\title{
Resilient Design and Adaptive Thermal Comfort in the Tropics
}

\author{
Daniel Zepeda-Rivas ${ }^{1}$, Jorge Rodríguez-Álvarez ${ }^{1,2}$ \\ ${ }^{1}$ Universidade A Coruña, A Coruña, Spain \\ ${ }^{2}$ Architectural Association School of Architecture, London, UK
}

\begin{abstract}
Weather data and a building model play a key role in predicting the environmental performance of buildings. While methods and parameters are broadly discussed, weather files, and specifically future scenarios, are not studied and compared in such an exhaustive manner. This paper explores the sensitivity of a thermodynamic digital model to various weather data, presenting a comparison of the simulation results for a case study under four climatic datasets. The first scenario represents the building as it was projected in the early 2000s; the second one describes the building performance during the year 2015. Finally, two scenarios of future performance (years 2050 and 2080). Fieldwork was carried out during the summer of 2015 to understand the real performance of the building and the user satisfaction. Results show a positive performance of the building through the different scenarios, as a consequence of the intrinsic application of passive strategies in architectural design. Overheating was also assessed using a novel method for humid subtropical climates, the method is based on a 4 point criteria using the EN-15251 comfort equation, it's objective is to quantify and characterize the overheating hours.
\end{abstract}

\section{Introduction}

Thermodynamic Building Simulation is one of the tools most frequently used to predict and assess the environmental performance of buildings. While simulation software and parameters have been broadly discussed so far, future weather data is not studied and compared in such an exhaustive manner (Coley et al., 2017).

The data contained on weather files have a direct impact on decision making during the design process of a building, nonetheless, due to climate change phenomena, they are proving to be increasingly inaccurate tools for estimating the future performance of buildings, especially for those with a life expectancy exceeding 30 years, bearing this in mind, the use of weather files with future predictions as common practice in future projects can ensure resilience, thus, resource utilization, comfort, and safety. (Dickinson and Brannon, 2016)

In line with this statement, the most recent report by the Intergovernmental Panel on Climate Change (IPCC) stressed the urgent need to limit global warming below $1.5^{\circ} \mathrm{C}$, and by November 2018,195 countries committed on a set of actions to confront the situation, requiring numerous changes in different fields. Ever since, and regardless of local legislation, architectural designers and consultants in these countries have spent many resources to improve building design aiming to target new energy and human requirements (Masson-Delmotte et al., 2018).

However, projected future scenarios are still rather compromising than relieving. Most published literature focuses on estimating energy demand and energy savings through different means (Sillmann et al., 2017; Kachkouch et al., 2018), leaving aside predictions of the environmental performance of building under the future climate conditions we may face (Taylor et al., 2014; Dickinson and Brannon, 2016; Coley et al., 2017) Very few studies have taken into consideration and simultaneously these two equally important aspects (Rodríguez Álvarez and Pintos Pena, 2016; Coley et al., 2017; Erba, Causone and Armani, 2017). Most related studies are focused on the validation of very specific methodologies for design projects with very specific characteristics, ignoring the possibility to estimate the extent of the potential effect of passive strategies. (Oropeza-Perez, Petzold-Rodriguez and Bonilla-Lopez, 2017; Preciado-Pérez and Fotios, 2017)

The relation of the Mexican climatic context with building performance has been explored in various ways before. Theoretical and experimental research projects have been focused on passive and low-energy architecture. (Gómez-Azpeitia et al., 2009; Marincic et al., 2009; Hernández-Pérez et al., 2014). More specifically, several studies address the estimation of thermal comfort together with the efficiency of passive means to achieve it. (Oropeza-Perez and Østergaard, 2014; Preciado-Pérez and Fotios, 2017). A common conclusion from these studies highlights that the mildness of the Mexican tropical and subtropical climate provides a great potential for achieving thermal comfort on free-running buildings.

The analysis presented in this paper focuses on the effectiveness of passive strategies as means to provide thermal comfort under current and future climate conditions. The aim of this work is to investigate the resilience of passive design in the Mexican context. Specifics of local climate play a key role in this type of evaluation, and therefore vulnerability to overheating is assessed. 


\section{Methodology}

This study represents a computational and empirical evaluation of the environmental performance of a freerunning building completed in 2006. The building is currently fully occupied and is located on a humid subtropical climate, in the city of Guadalajara, Mexico. The building (Figure 1), designed by the Spanish architectural firm Estudio Carmen Pinos, was intended as a landmark of sustainable design, since it only relies on passive strategies to create and maintain thermal comfort.

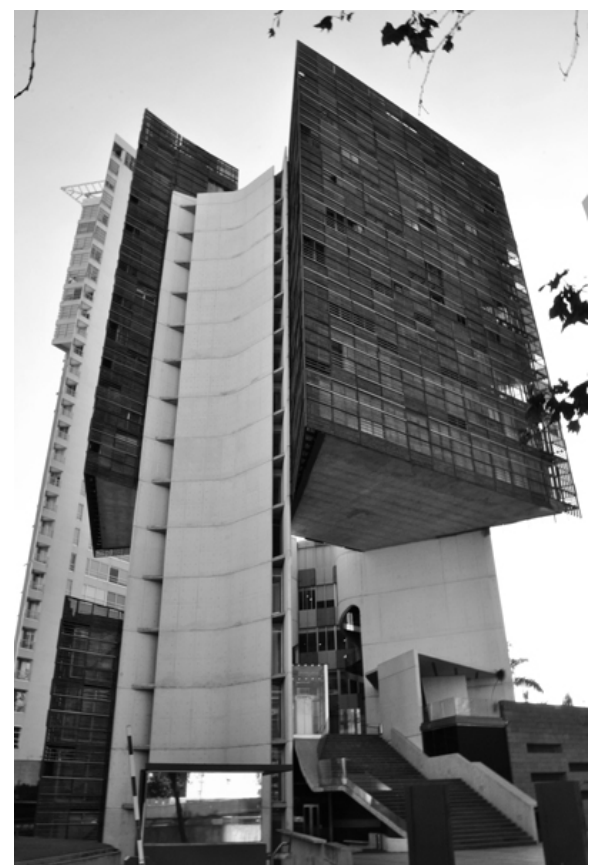

Figure 1: Photograph of the façade of the building.

While the aesthetics of the building may be contrasting with the local context, materials and construction methods were used following those in local edifications. Correspondingly, passive strategies were also selected based on learnings from contemporary and vernacular architecture, namely, shading devices for solar protection, solid thick walls for thermal mass, and natural cross ventilation and night cooling to enhance the thermal balance.

\section{Weather Data}

Different weather information from the same location was collected and compared with the intention of creating a hypothetical chronological path in order to evaluate the building's response to a changing climate (i.e. its resiliency):

1. The first simulation used normalized weather data, stored as an EPW file sourced from Meteonorm 7.2. Data were obtained from a 30 year radiation period (1991-2010) and a 10 year temperature period (2000-2009). This weather data intended to replicate the kind of data used at the time the building was designed.

2. The second weather dataset was extracted from a global weather database, containing the specifict data collected during the year 2015 at the same station previously used.

3. The third and fourth weather files were generated with the tool "The climate change world weather generator" (CCWorldWeatherGen) using the first EPW file as a base file (Jentsch et al., 2013). The tool uses the IPCC's Third Assessment report model summary data of the HadCM3 A2 experiment to apply a "Morphing" methodology for climate change transformation of weather data (Belcher, Office and Hacker, 2005). These files are predictions of future scenarios for the years 2050 and 2080. The scenario used was the A2, which assumes a regionally oriented economic development and a global warming range from 2.0 to $5.4^{\circ} \mathrm{C}$ for the year 2100 , being the second worse scenario after the A1F1 (Masson-Delmotte et al., 2018). The CCWorldWeatherGen tool was chosen as a future scenario generator, considering that unlike others tools of its kind, it modifies with statistically significant changes all the values comprised on the morphed file, values such as the different types of radiation that take a significant role on building thermal simulations (Moazami, Carlucci and Geving, 2017).

A graphical comparison of the four different datasets is presented in Figure 2. The chronological progressive effect of global warming can be noticed, as well as the effect of the morphing methodology on future files.

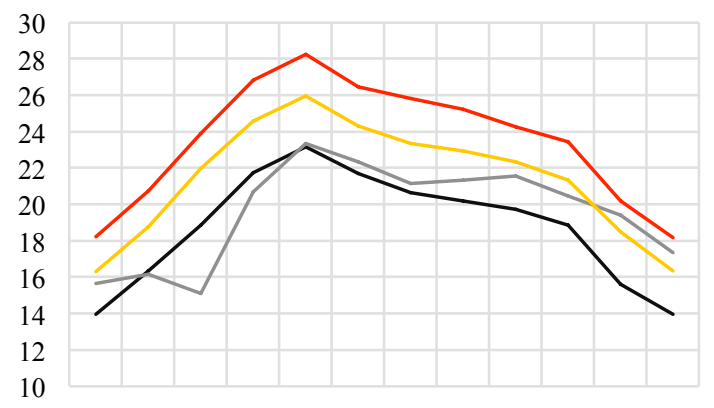

Jan Feb Mar Apr May Jun Jul Aug Sep Oct Nov Dec

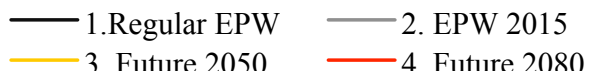

Figure 2: Comparison of mean the monthly values of temperature of each file

Weather data and climatic analyses were carried out in order to understand climate's challenges and opportunities. As a result, it was confirmed that due to the mildness of the weather, comfort could be achieved for all through the year using only passive strategies (Figure 3). The most effective strategies for this location were passive solar heating in the cold seasons such as December and January, and thermal mass, solar protection, night cooling and natural ventilation for the rest of the year, when overheating is the main problem. Moreover, it was identified that the most valuable climatic quality of the location was the diurnal temperature variation. However, this variation is 
presented differently throughout the year. During spring months (i.e. March and April), the average diurnal temperature variation is 18.06 and $17.84^{\circ} \mathrm{K}$, while during summer months (i.e. July and August) is only 8.35 and $8.62^{\circ} \mathrm{K}$, as a result of unobstructed solar radiation and cloud cover. These swings are represented in Figure 4.

\section{Building Elements}

During August 2015, fieldwork was carried out in one of the offices of the building. The main objective of the fieldwork was to monitor the actual performance of the building and to get feedback about general user satisfaction, thus, data loggers were used to measure indoor temperature, and surveys and questionnaires for the user satisfaction.

One of the major findings from the fieldwork was to spot the differences between the actual internal conditions and the conditions suggested in the literature (DOE, 2004; American Society of Heating, 2010). The internal gains found in the building were around $45 \mathrm{w} / \mathrm{m}^{2}$, while the ones recommended were between 25 and $30 \mathrm{w} / \mathrm{m}^{2}$. The occupancy loads as a consequence of equipment and people were higher in the building than in literature, although the schedules of use presented fewer active hours. Another spotted difference was the heat gains produced by lighting loads. The ones found in the building were lower, both in terms of heat loads and hourly use, mainly as a consequence of the tropical sky luminance and the design of the building. Figure 5 shows the hourly internal gains during a 24-hour period. One more finding from the fieldwork was the user's thermal satisfaction of the building. The general outcome for the specific period of the evaluation ranged from slightly warm to slightly cool. The fieldwork was also used to identify specific details of occupant behaviour, such as the actual schedules of personnel and operation of lighting and windows, although these will not be discussed in the paper.

A thermodynamic digital model of the building was elaborated using Honeybee for Rhino Grasshopper and Energy plus as a simulation engine. The building specifications were provided by the facility manager and the thermal model was calibrated using the same exact time period found on the EPW from 2015, together with the previously mentioned information gathered during the fieldwork. As a result, the simulation output was calibrated to match the data from the data loggers during that specific time. Figure 6 shows the temperature and radiation from the weather file, as well as data from the internal data logger and the modelled air temperature.

Table 1 and 2 present general specifications of building materials. The construction materials of the building are mostly simple and exposed. The exterior walls are made and finished with exposed concrete on the interior and exterior faces, as well as in the underside of the floor slab, providing direct access to thermal mass to most of the interior surfaces.
The exterior windows are made of single glazing with aluminium framing, and the shading, the furniture on the interior of the office suite are mainly made of solid wood or plywood, and the internal walls are made of regular gypsum.

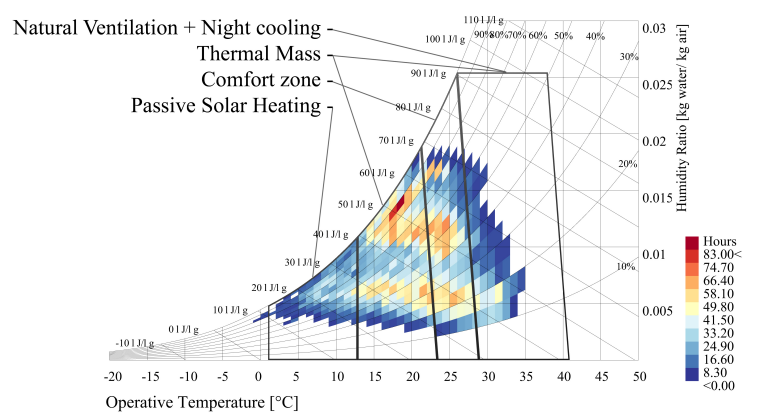

Figure 3: Psychrometric chart with passive strategies (regular EPW)

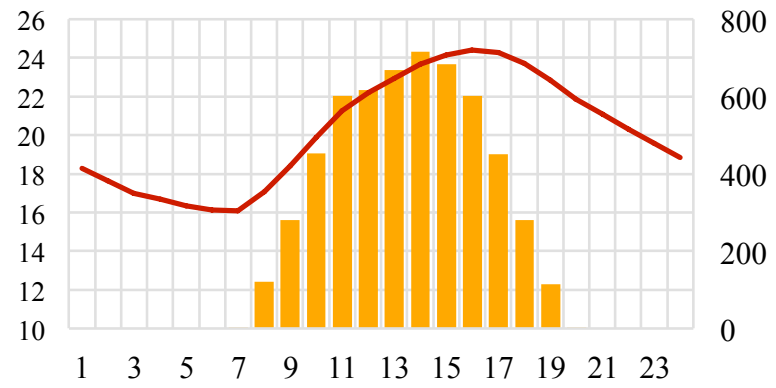

Hourly average global horizontal radiation $[\mathrm{Wh} / \mathrm{m} 2]$
Hourly average dry bulb temperature $\left[{ }^{\circ} \mathrm{C}\right]$

Figure 4: Diurnal average variation during August (regular EPW)

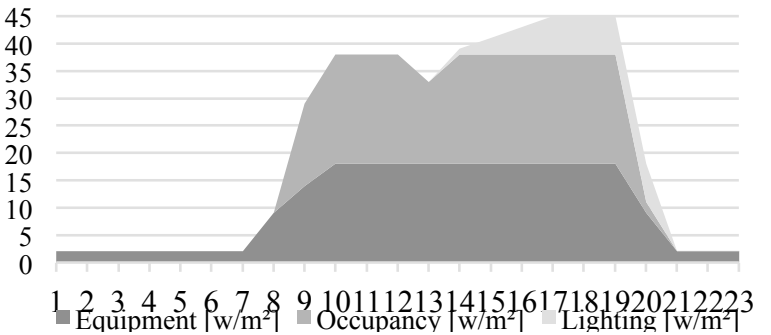

Figure 5: Hourly internal gains during a $24 \mathrm{hr}$ period.

Table 1 \& 2: Building materials and general specifications

\begin{tabular}{|c|c|c|}
\hline Element & Material & U-Value \\
\hline Exterior Walls & Concrete & $2.8 \mathrm{~W} / \mathrm{m}^{2} \mathrm{~K}$ \\
\hline Interior Walls & Gypsum & $2.5 \mathrm{~W} / \mathrm{m}^{2} \mathrm{~K}$ \\
\hline Exterior Windows & Single Glazing & $5.3 \mathrm{~W} / \mathrm{m}^{2} \mathrm{~K}$ \\
\hline Shading & Wood & $5.9 \mathrm{~W} / \mathrm{m}^{2} \mathrm{~K}$ \\
\hline
\end{tabular}

\begin{tabular}{|c|c|}
\hline Interior surface & $105.7 \mathrm{~m}^{2}$ \\
\hline Interior volume & $370 \mathrm{~m}^{3}$ \\
\hline WFR & 0.69 \\
\hline WWR & 0.74 \\
\hline Infiltration & $1 \mathrm{ACH}$ \\
\hline Interior Height & $3.00 \mathrm{~m}$ \\
\hline
\end{tabular}


$32{ }^{\circ} \mathrm{C}$

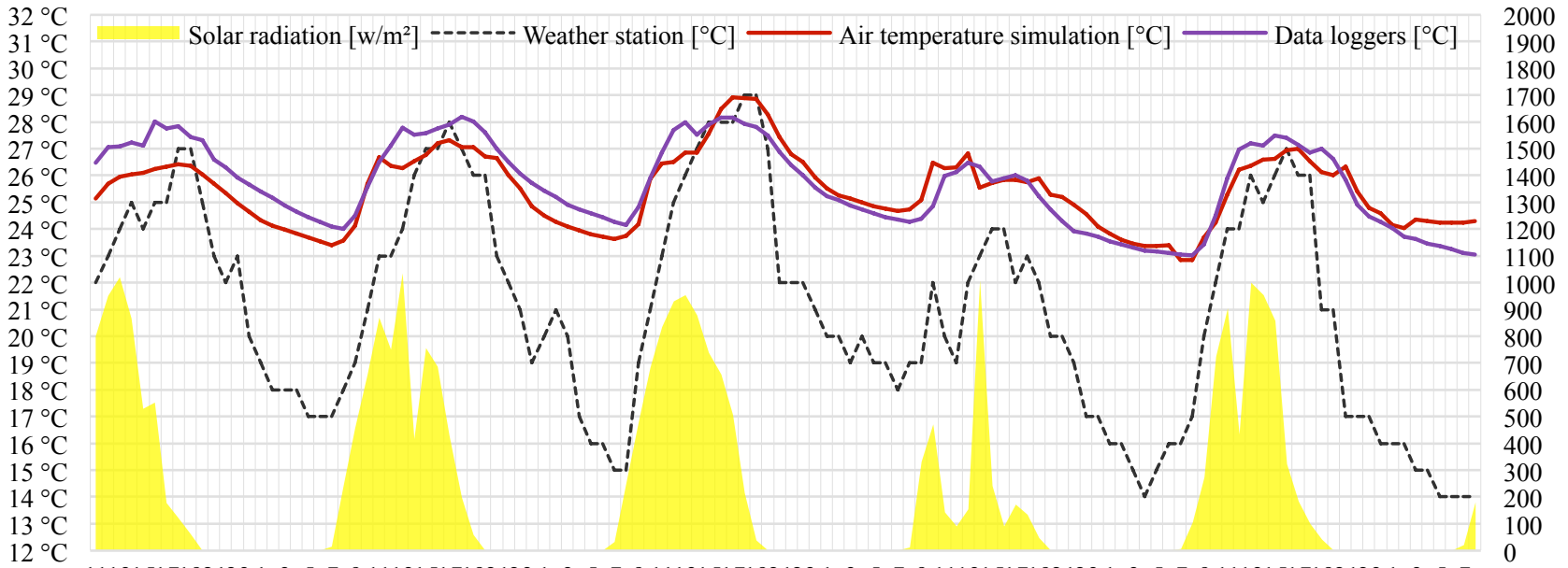

1113151719212313579111315171921231357911131517192123135791113151719212313579111315171921231357

Figure 6: Calibration graph with temperatures of data logger, weather station and simulation model

After building and calibrating the 3D model, the simulation process was repeated four different times using the aforementioned weather scenarios (i.e. early 2000s, 2015, 2050 and 2080). Building model, material specifications or internal conditions were not modified at any moment. The only parameters that changed between simulations were the window ventilation parameters.

The occupants' behaviour regarding windows operation was observed during the fieldwork. In general, the windows were only open during occupancy time. The first occupants to arrive in the morning (9:00 a.m.) would open some of them slightly; then later around noon, as temperatures rise during the day, occupants would open all or most of them, depending on the general internal thermal sensation. This pattern was used initially to calibrate the model. Nevertheless, after a first sensitivity analysis, it was noticed that comfort hours could be improved by increasing the window opening area and decreasing the maximum indoor temperature for natural ventilation, from the original $29^{\circ} \mathrm{C}$ found on the fieldwork to $24^{\circ} \mathrm{C}$. This setting was used for the first two simulated scenarios. For the future 2050 and 2080 scenarios, a window opening of a $5 \%$ was configured during non-occupancy hours as night cooling, for the purpose of preparing the building for the next day. This setting was tested on the first two scenarios, but it was discarded since the temperature of the building would fall below the lower comfort limit at the beginning of the day.

Thermal comfort was evaluated using the European standard BS EN-15251 for naturally ventilated buildings (BSI, 2008). The main difference between the EN-15251 and the ASHRAE standard 55 resides in the inconstant variables on the equation, where the ASHRAE 55 uses $\mathrm{T}_{\mathrm{o}} \mathrm{m}$ calculated as the monthly mean temperature, the EN-15251 uses $T_{r}$ or exponentially weighted running mean of the daily mean outdoor air temperature (CIBSE, 2013). While the measurement of outdoor temperature for this purpose has commonly been the monthly mean, the use of an exponentially weighted running mean of the recently endured temperatures, provides a more certain relation with the thermal history of the subject giving more influence to the recent experiences (i.e. the constant high temperatures during a heatwave). It is possible to say that the EN-15251 is better suited to predict thermal stress induced by overheating since it takes into account the ability to adapt and acclimatize (Nicol, Humphreys and Roaf, 2012). Moreover, previous studies on Mexican territory have proved better results using this comfort equation. (Marincic et al., 2009; Gómez-Azpeitia et al., 2012).

After the digital models were completed and tested with the four different weather files, the plausibility of overheating was measured as the main source of thermal discomfort. Overheating in a building occurs either as a consequence of poor design, poor management or inadequate services (CIBSE, 2013). On this specific case, the last two possibilities will be discarded since the subject is a free-running building where the occupants have direct access to the window operation. Thus, the resilience and adeptness of the whole building will be measured, including its design qualities and materials.

\section{Overheating Assessment}

It is considered that a building is overheated when a given significative proportion of people in a building are under thermal stress as a consequence of higher temperatures than the ones expected. While thermal comfort on mechanically cooled buildings is predicted using a direct application of a PMV PPD index (Nicol, Humphreys and Roaf, 2012), in non-mechanically controlled buildings such as free-running buildings, it is measured as the outer temperature above a determined range around a neutral temperature (CIBSE, 2013). Even though this neutral temperature is directly associated with an external environmental condition, it is not clear what is the actual extent of this range since it is often very difficult to determine due to the many variables involved (Humphreys, Rijal and Nicol, 2013). For this specific case, a comfort band of $\pm 4 \mathrm{~K}$ around the thermal neutrality will be considered, assuming $80 \%$ of acceptability limits in consideration of the availability of adaptive opportunities. 
Even when most of the literature on thermal comfort clearly establishes the general limits of what can be considered as thermal comfort, the exact limits of overheating in this context are not clearly drawn. The question of how much overheating is too much in a freerunning workspace located in a tropical or subtropical Latin-American context remains still unclear. Concerning the measurement of overheating, there are many approaches to measure it according to different purposes. Most of the previously mentioned works take into account overheating only as the percentage of the time above the upper comfort limit. Consequently, the results do not show the extent and intensity of the exceedance. The document CIBSE TM52 suggests, instead, a methodology based on three criteria (i. e. hours of exceedance $\geq 1 \mathrm{~K}$, daily weighted exceedance and upper limit temperature above $4 \mathrm{~K}$ ) to assess the risk of overheating in new naturally ventilated buildings in the UK and Europe. This is one of the most accepted and broadly used methods to assess overheating, although it has been found that it fails to reveal stretches of time where heat stress persists continuously (Lee and Steemers, 2017). However, the application of this method in a tropical context could be questioned relying on the fact that is based on previous work developed in a European context (Nicol, Humphreys and Roaf, 2012).

This paper proposes a simpler method (Zepeda-Rivas, Daniel and Rodríguez-Álvarez, 2019) to measure the intensity of overheating under a humid subtropical climate in a sensitive manner. It also utilizes on the EN15251 comfort equation and comfort band extent. According to the distance to the upper comfort limit, it classifies and enumerates the hours in four different categories:

- The number of hours $>0.1 \mathrm{~K}$. The total amount of hours where the temperature is above comfort regardless of how far from comfort they are, although this number may not be meaning full at first, it importance arises when compared to the other 3 categories. The number of hours may represent in a strict way, the total of time outside of the comfort limit, but not necessarily, indicate an overheating problem since a temperature change of less than $1^{\circ} \mathrm{K}$ is almost imperceptible to the body (Nicol, Humphreys and Roaf, 2012).

- The number of hours $>1 \mathrm{~K}$. The total amount of hours where the temperature is one whole degree or more above comfort. This is where thermal stress begins to be present on very sensitive subjects, the resultant hours after subtracting the hours $>2 \mathrm{~K}$ and $>3 \mathrm{~K}$, is the actual number of hours where one or many adaptive opportunities can be highly effective against thermal stress. This can be summarized as the possibility of changing the surrounding environment as for example, access to cold drinks, air flow improvement, and clothing adjusments.

- The number of hours $>2 \mathrm{~K}$. The total amount of hours where the temperature is two degrees or more above comfort. This is where thermal stress is already present and something should be done in order to regain comfort. This would require access to more than one passive opportunity since the effect of multiple passive opportunities can be accumulative and psycologically relieving.

- The number of hours $>3 \mathrm{~K}$. The total amount of hours where the temperature is three degrees or more above comfort. In practical terms, this would mean temperatures above $33^{\circ} \mathrm{C}$, at this temperature thermal stress is a problem for occupants and cannot be endured for long periods without without experiencing discomfort despite adaptive opportunities. A high number of these hours during occupancy time means that a building is prone to overheat, and thermal comfort is frequently compromised.

The extent and persistence of the overheating phenomena can be inferred through these numbers, but only when applying this method accounting for the total of both occupancy and non-occupancy hours. The number of hours $>3 \mathrm{~K}$ stand for the total of hours outside comfort. In a graphical way, this means that the parabola followed by the temperatures at some point crossed two times the $+2 \mathrm{~K}$ and $+1 \mathrm{~K}$, once when increasing, and again when decreasing. Thus, it is possible to find out when the $+2 \mathrm{~K}$ and $+1 \mathrm{~K}$ temperatures occur as an isolated event, or as part of further heat accumulation. This can be found by multiplying the number of hours $>3 \mathrm{~K}$ by two and then, subtracting separately the result to the number of hours $>2 \mathrm{~K}$ and $>1 \mathrm{~K}$. The resulting number on each of the categories is the number of hours when overheating occurred and did not escalate further due to the presence of passive strategies. The difference is the number of hours when overheating occurred as part of a constant heat accumulation, still manageable with adaptive opportunities but at some point their effectiveness will declined depending on the total intensity.

\section{Results and Discussion}

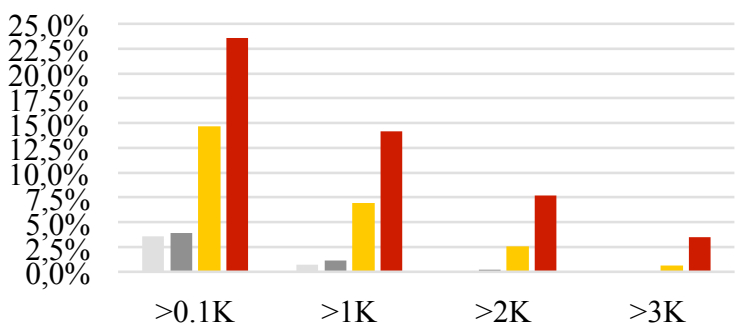

$$
\begin{array}{ll}
\text { Regular EPW } & \text { Y2015 EPW } \\
\text { F2050 EPW } & \text { F2080 EPW }
\end{array}
$$

Figure 7: Overheated occupancy hours

Following the above-mentioned methodology, results from the four different climate scenarios were computed and plotted into two different graphs. Figure 8 shows the accumulative count of overheating hours, while Figure 7 shows the percentage of overheating time during occupancy hours. 


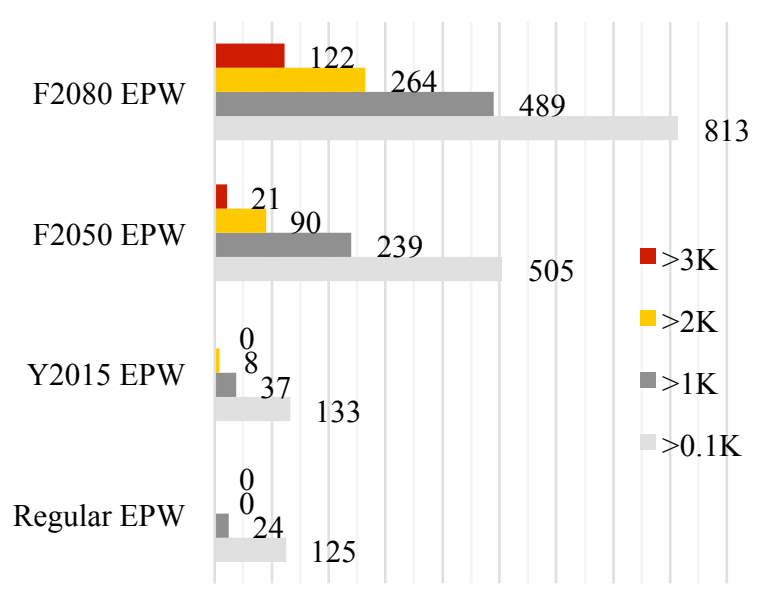

$0 \quad 100200300400500600700800900$

Number of hours

Figure 8: Overheated percentage of time

On first sight, it is possible to appreciate a chronological progressive increase of overheating in the same way as it was presented on the weather files (Figure 3). The slight increase between scenario 1 (regular EPW) and scenario 2 (EPW from 2015) can be explained due to the chronological proximity of both scenarios, and therefore, the increase in the future scenarios 3 and 4 (2050 and 2080 respectively) is more noticeable.

The high number of hours corresponding to the occupancy hours and percentage of time above $>0.1 \mathrm{~K}$ across the four different cases can be referred as a sensible count to measure the chronological propensity to overheat due to the weather conditions. Yet, not all that time can be accounted as effective time overheated as it was previously explained. However, on the first two scenarios, the chronological increase of overheating during occupancy hours and percentage of time above $1 \mathrm{~K}$ and $2 \mathrm{~K}$ can be interpreted as an eventual increase of thermal discomfort that could be tackled with adaptive opportunities, since they happen as isolated events and no further overheat is recorded on the $>3 \mathrm{~K}$. For the case of the 21 hours above comfort on the future scenario corresponding to 2050 , they only represent $0.6 \%$ of occupied time during the springtime spread acorss the months of March, April and May, and therefore not representing an overheating problem.

In the case of the second future scenario (2080), the 122 hours above $3 \mathrm{~K}$ correspond to a $3.5 \%$ occupancy time predicted as overheating. In figure 9 it is possible to appreciate a typical 24-hour lapse where this occurs. The BS EN 15251 suggests a maximum of $3 \%$ of occupied hours as the limit of overheating in naturally ventilated new edifications. Although the EN 15251 refers to the time exceeding temperatures above $1 \mathrm{~K}$, for the purpose of this research it has been moved to $3 \mathrm{~K}$. Thus, in this specific case it can be inferred that the building is prone to overheat during spring, but yet, manageable, and it is not necessarily a recurring problem during the other seasons of the year.

The original 3\% maximum of occupied hours above $1 \mathrm{~K}$ exceedance limit is established in the EN-15251 and supported by the insights of thermal studies elaborated on a European context. During those same studies, it was determined that the limit of thermal comfort for European naturally ventilated buildings is $30^{\circ} \mathrm{C}$, since the thermal sensation of the subjects reported above that temperature was mostly " +3 Hot" and " +2 Warm" on a PPD PMV scale (Humphreys and Nicol, 2002; Humphreys, Rijal and Nicol, 2013). Nevertheless, comfort studies elaborated on a Mexican context have concluded that due to the adaptation and acclimatization of the people living in this context, the same limit could be drawn at $33^{\circ} \mathrm{C}$ (Marincic et al., 2009; GómezAzpeitia et al., 2012).

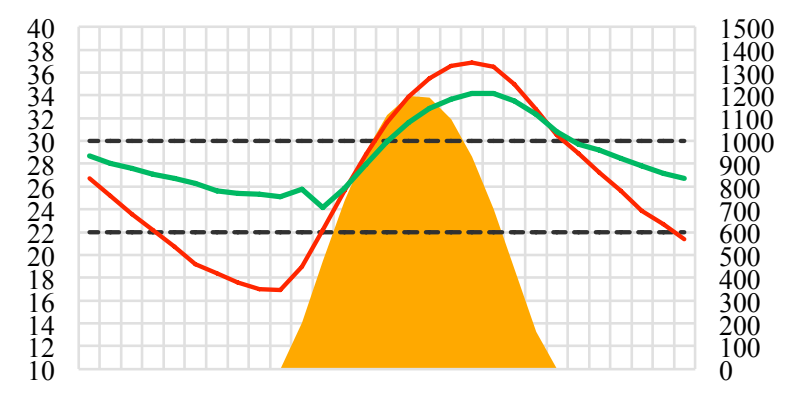

$22 \quad 24 \quad 2 \quad 4 \quad 6 \quad 8 \quad 1012 \quad 14 \quad 16 \quad 182022 \quad 24 \quad 2$

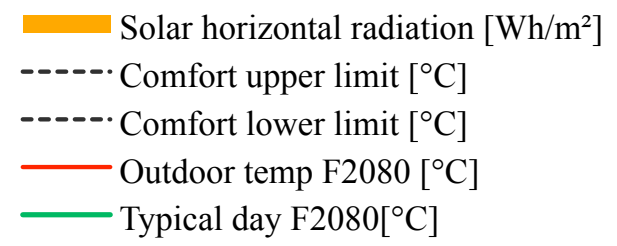

4. Figure 9: 24hr lapse during a typical day with overheating (EPW F2080)

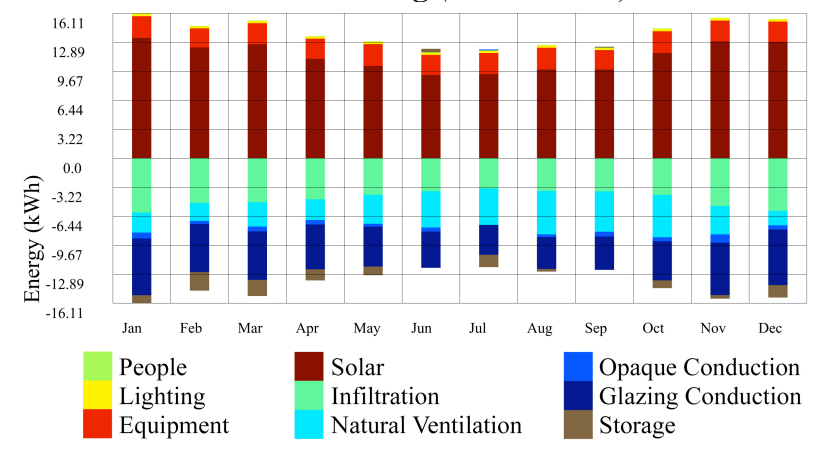

Figure 10: Energy Balance of the simulated year (EPW F2080)

After the results of the overheating analysis, the following matter is the performance of the building. As it was stated before, the environmental criteria on which the building is based can be summarized as solar protection against the solar radiation, thermal mass to induce heat lag and natural ventilation with the possibility of natural crossed ventilation and night cooling. The application of these strategies along with the design of the building is responsible for the actual performance of the building. 
Figure 10 describes the energy balance of heat gains and losses of the simulated zone of the building. It is possible to appreciate the extent and scale of the heat gains and losses, where the main source of heat gains are the solar gains and the main outflow of heat losses are infiltration and natural ventilation. Even though the actual internal gains of the building were higher than those suggested by literature, the equipment, people and lighting gains do not have as much as individual impact as the external conditions. On the other side, natural ventilation and infiltration are those with the greatest cooling effect, followed by the heat losses through the glazing materials and walls. Lastly, the effect of the thermal mass, even though its influence seems to be minimal compared to the others, it is important to remark its influence on the resultant temperature, since it directly affects the mean radiant temperature of the interior surfaces of the building.

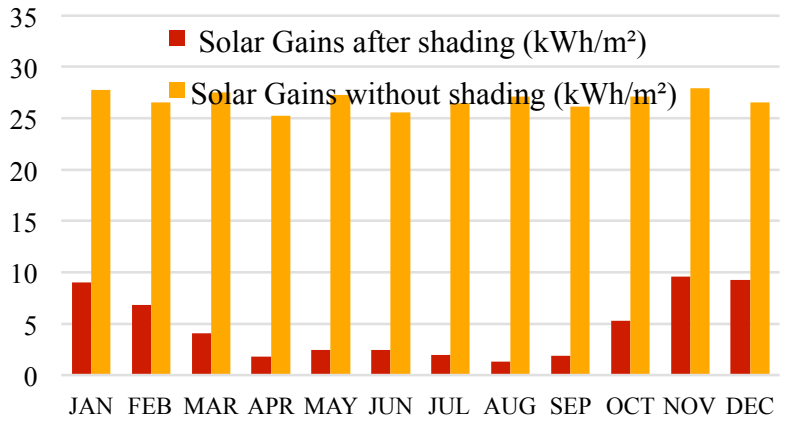

Figure 11: Share of solar gains hitting the building versus the actual solar gains at the interior of the building.

The greatest responsible for the inflow and outflow of energy is the glazing. Nowadays it is unlikely to find a large whole façade or glazing surface with a high Uvalue of $5.3 \mathrm{~W} / \mathrm{m}^{2} \mathrm{~K}$ as the one found in this particular building. However, the solar protection compensate this effect during the daytime, and as for the night time, it proves to be an efficient way to help discharge the gained heat during the day. On Figure 11 it is possible to appreciate the share of solar gains that were not blocked either by the shading device nor the glazing, even when this share of solar gains could be reduced with glazing with a higher resistance, it would be counterproductive for the night time energy outflow.

\section{Conclusions}

This study is set out to investigate whether a building designed with environmental criteria supported by passive strategies is prepared to face future weather conditions and the possible effects of climate change in the shape of overheating. This study was also designed to investigate the current effectiveness of these passive strategies under current climatic conditions. The building performance under the four different scenarios was surprisingly better than expected, remaining in comfort for most of the occupancy time through the year. The main contributing factor for this result was the diurnal temperature range that prevailed during the different simulated scenarios, as well as the limited differential of sun hours through the year. Considering this, it was possible to take advantage of overnight nigh cooling and almost eliminate the accumulated heat during the day. The design of the building is also a major key role since it joins on a very efficient way the different passive strategies. Moreover, the double façade that includes a shading device and glazing with low resistance, together with thermal mass, are the key factors for the performance of the building. With all these findings, the resiliency of the building was proved through the simulation process. Further analysis must be pursued in order to establish how the building envelope could be altered to improve its performance and make it more resilient. While the specific environmental conditions that we may face in the future are still developing, with the data presented on this work it is possible to say that we may still be able to face them with the sole use of passive strategies. The uncertainty of this last statement resides in the fact that the climate shift that we may experience during the future years could probably exceed our human capacity to adapt and acclimate, since the predicted temperature on this specific location is in a really close range to the human core temperature. However, the main limitation of this evaluation is the incapacity to demonstrate the exact time extend where overheat persist continuously.

\section{Acknowledgement}

The authors will like to thank Dr. Dru Crawley from climate.onebbuilding.org and Meteoblue AG Switzerland, for their contribution to this paper providing access to weather data. Also, to CUBE Corporation, Estudio Carme Pinos and Alberto Tacher for providing access, information and useful documents of the building.

\section{References}

American Society of Heating, R. and A.-C. E. (2010) ANSI/ASHRAE Standard 55-2010: Thermal Environmental Conditions for Human Occupanc. Edited by R. and A.-C. E. American Society of Heating. Atlanta, GA.

Belcher, S. E., Office, M. and Hacker, J. N. (2005) 'Constructing design weather data for future climates', (February). doi: 10.1191/0143624405bt112oa.

BSI (2008) 'UNE-EN 15251:2008. Indoor environmental input parameters for design and assessment of energy performance of buildingsaddressing indoor air quality, thermal environment, lighting and acoustics', Aenor, pp. 152. doi: 10.1520/E2019-03R13.Copyright.

CIBSE (2013) 'The limits of thermal comfort : avoiding overheating in European buildings', CIBSE Tm52, pp. 1-25. doi: 10.1017/CBO9781107415324.004.

Coley, D. et al. (2017) 'Probabilistic adaptive thermal comfort for resilient design', Building and Environment. Elsevier Ltd, 123, pp. 109-118. doi: 10.1016/j.buildenv.2017.06.050. 
Dickinson, R. and Brannon, R. (2016) 'Generating Future Weather Files for Resilience', PLEA 2016: 36th International Conference on Passive and Low Energy Architecture.

DOE (2004) No Title, Commercial Reference Buildings. Available at: https:/www.energy.gov/eere/buildings/commercialreference-buildings.

Erba, S., Causone, F. and Armani, R. (2017) 'The effect of weather datasets on building energy simulation outputs', Energy Procedia. Elsevier B.V., 134, pp. 545-554. doi: 10.1016/j.egypro.2017.09.561.

Gómez-Azpeitia, G. et al. (2012) 'Extreme adaptation to extreme environments: case study of hot dry, hot sub-humid, and hot humid climates in Mexico', Proceedings of the 7th Windsor Conference: The Changing Context of Comfort in an Unpredictable World., 8(8), pp. 12-15. doi: 10.17265/19347359/2014.08.001.

Gómez-Azpeitia, G. . et al. (2009) 'Comfort temperatures inside low-cost housing: Case: Six warm climate cities in Mexico', PLEA 2009 Architecture Energy and the Occupant's Perspective: Proceedings of the 26th International Conference on Passive and Low Energy Architecture, (June), pp. 22-24. Available at: http://www.scopus.com/inward/record.url?eid=2s2.0-

84855609370\&partnerID $=40 \& \mathrm{md} 5=\mathrm{a} 07655 \mathrm{~b} 4 \mathrm{abeed}$ $786 \mathrm{ffd} 7 \mathrm{ce} 1 \mathrm{~d} 3 \mathrm{c} 389266$.

Hernández-Pérez, I. et al. (2014) 'Thermal performance of a concrete cool roof under different climatic conditions of Mexico', Energy Procedia. Elsevier B.V., 57(777), pp. 1753-1762. doi: 10.1016/j.egypro.2014.10.164.

Humphreys, M. A. and Nicol, J. F. (2002) 'Adaptive thermal comfort and sustainable thermal standards for buildings', Energy and Buildings, 34(6), pp. 563572. doi: 10.1016/S0378-7788(02)00006-3.

Humphreys, M. A., Rijal, H. B. and Nicol, J. F. (2013) 'Updating the adaptive relation between climate and comfort indoors; new insights and an extended database', Building and Environment. Elsevier Ltd, 63, pp. 40-55. doi: 10.1016/j.buildenv.2013.01.024.

Jentsch, M. F. et al. (2013) 'Transforming existing weather data for worldwide locations to enable energy and building performance simulation under future climates', Renewable Energy. Elsevier Ltd, 55, pp. 514-524. doi: 10.1016/j.renene.2012.12.049.

Kachkouch, S. et al. (2018) 'Experimental assessment of thermal performance of three passive cooling techniques for roofs in a semi-arid climate', Energy and Buildings. Elsevier B.V., 164, pp. 153-164. doi: 10.1016/j.enbuild.2018.01.008.

Lee, W. V. and Steemers, K. (2017) 'Exposure duration in overheating assessments: a retrofit modelling study', Building Research and Information. doi: 10.1080/09613218.2017.1252614.

Marincic, I. et al. (2009) 'Adaptive Thermal Comfort in Warm Dry Climate: Economical dwellings in Mexico', 26th Conference on Passive and Low Energy Architecture, Quebec City, Canada, (June), pp. 22-24.

Masson-Delmotte, V. et al. (2018) Global warming of $1.5^{\circ} \mathrm{C}$ An IPCC Special Report. Incheon, Republic of Korea: Intergovernmental Panel on Climate Change (IPCC). doi: 10.1017/CBO9781107415324.

Moazami, A., Carlucci, S. and Geving, S. (2017) 'Critical Analysis of Software Tools Aimed at Generating Future Weather Files with a view to their use in Building Performance Simulation', Energy Procedia. Elsevier B.V., 132, pp. 640-645. doi: 10.1016/j.egypro.2017.09.701.

Nicol, F., Humphreys, M. and Roaf, S. (2012) Adaptive Thermal Comfort, Principles and Practice. London: Routledge.

Oropeza-Perez, I. and Østergaard, P. A. (2014) 'The influence of an estimated energy saving due to natural ventilation on the Mexican energy system', Energy. Elsevier Ltd, 64, pp. 1080-1091. doi: 10.1016/j.energy.2013.11.009.

Oropeza-Perez, I., Petzold-Rodriguez, A. H. and Bonilla-Lopez, C. (2017) 'Adaptive thermal comfort in the main Mexican climate conditions with and without passive cooling', Energy and Buildings. Elsevier B.V., 145, pp. 251-258. doi: 10.1016/j.enbuild.2017.04.031.

Preciado-Pérez, O. A. and Fotios, S. (2017) 'Comprehensive cost-benefit analysis of energy efficiency in social housing. Case study: Northwest Mexico', Energy and Buildings. Elsevier B.V., 152, pp. 279-289. doi: 10.1016/j.enbuild.2017.07.014.

Rodríguez Álvarez, J. and Pintos Pena, S. (2016) 'A Climatic Cartography for Sustainable Housing: Development of a meteorological classification in Galicia , Spain', 1. Available at: http://www.plea2016.org/download/PLEA 2016 Volume 1.pdf.

Sillmann, J. et al. (2017) 'Understanding, modeling and predicting weather and climate extremes: Challenges and opportunities', Weather and Climate Extremes. Elsevier Ltd, 18(November), pp. 65-74. doi: 10.1016/j.wace.2017.10.003.

Taylor, J. et al. (2014) 'The relative importance of input weather data for indoor overheating risk assessment in dwellings', Building and Environment. Elsevier Ltd, 76, pp. 81-91. doi: 10.1016/j.buildenv.2014.03.010.

Zepeda-Rivas, Daniel and Rodríguez-Álvarez, J. (2019) 'Asssessing overheating risk and adaptive thermal comfort in the tropics', Unpublished Work. 